ORIGINAL PAPERS

\title{
Malaria remains a military medical problem
}

\author{
M J World
}

\begin{abstract}
Objective: To bring military medical problems concerning malaria to the attention of the Defence Medical Services

Method: Seven military medical problems related to malaria are illustrated by cases referred for secondary assessment over the past five years. Each is discussed in relation to published data.

Results: The cases of failure of various kinds of chemoprophylaxis, diagnosis and treatment of malaria may represent just a fraction of the magnitude of the overall problem but in the absence of reliable published military medical statistics concerning malaria cases, the situation is unclear.

Conclusion: Present experience suggests there are a number of persisting problems affecting the military population in relation to malaria. Only publication of reliable statistics will define their magnitude. Interim remedies are proposed whose cost-effectiveness remains to be established.
\end{abstract}

\section{Introduction}

A number of problems persist in relation to malaria. Although they occur in the military population they are by no means confined os to it. However, when any medical problem $\overrightarrow{0}$ occurs in the military population, there are $\overrightarrow{\vec{H}}$

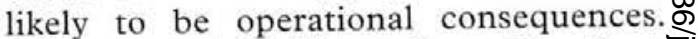
Failure to identify and tackle these $\overrightarrow{\overrightarrow{\mathrm{g}}}$ problems could result in the risk of a? significant reduction in operational capability. These problems include:

a) failure to take any chemoprophylaxis

b) side effects of antimalarial chemoprophylaxis

c) failure to take mefloquine chemoprophy- $\vec{\rho}$ laxis correctly

d) failure of mefloquine chemoprophylaxis

e) restriction of aircrew to chloroquine and proguanil chemoprophylaxis

f) failure to diagnose malaria

g) failure of malaria to respond to treatment with quinine

This paper describes cases that were referred for a secondary assessment andळ which illustrate these problems. Each is evaluated with reference to relevanto published data in order to formulate remedies.
Col MJWorld BSc MD FRCP L/RAMC

Professor of Military Medicine

Royal Defence Medical College, Gosport, Hampshire, PO12 2AB e-mail:

DrMikeWorld@cs.com

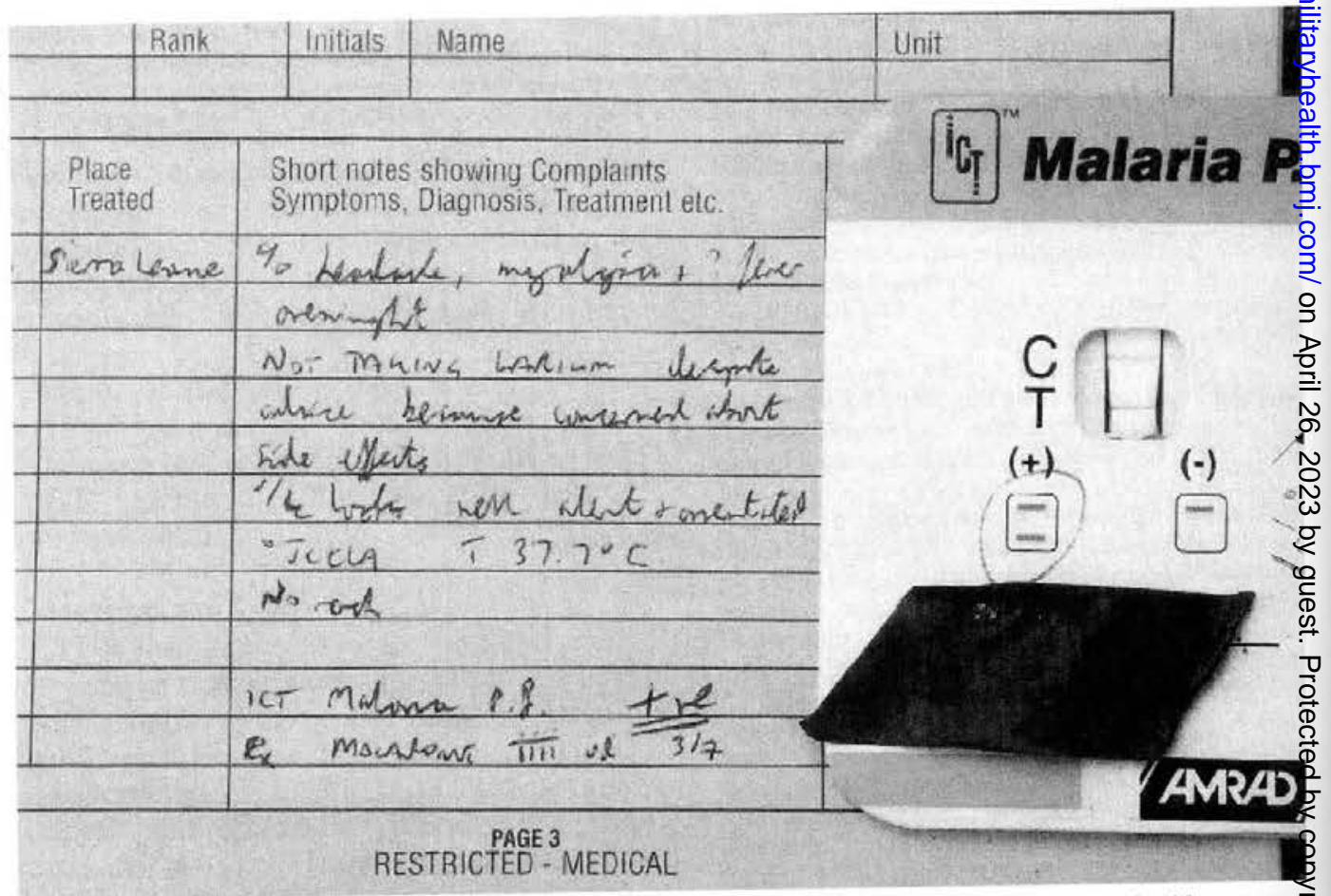

Fig 1. F Med 5 and positive ICT Malaria P.fM card test of soldier in Sierra Leone who presented with symptont흐. compatible with malaria, having failed to take mefloquine chemoprophylaxis because of concern about side effects? (Photograph courtesy of $\mathrm{Lt}$ Col Df Vassallo RAMC) 
Cases illustrating the problems

a) Failure to take any chemoprophylaxis

Some combatant personnel refuse to take any chemoprophylaxis. At least one such case (Case 1) arose during Operation PALLISER in Sierra Leone in May 2000 (Lt Col DJ Vassallo - personal communication). Malaria was diagnosed in the soldier concerned by ICT Malaria P. ${ }^{\mathrm{TM}}$ card test which detects the presence of antibodies to the histidine-rich protein of Plasmodium falciparum. He was treated with Malarone (atovaquone $250 \mathrm{mg}$ with proguanil $100 \mathrm{mg}$ ) 4 tablets orally once daily for 3 days and made a good recovery (See Figure 1).

\section{b) Side effects of antimalarial chemoprophylaxis Case 2}

A 26 years old Private $(\mathrm{PH})$ with no personal or family history of neuropsychiatric illnesses experienced a visual hallucination of the grim reaper standing behind the chaplain and this was associated with an auditory hallucination consisting of incoherent voices. This isolated attack lasted 15 minutes and occurred 2 days after taking his sixth weekly mefloquine tablet. Mefloquine prophylaxis was discontinued and doxycycline $100 \mathrm{mg}$ daily was substituted. The soldier was flown back to UK before the scheduled end of the exercise. $\mathrm{He}$ remained well thereafter. Further details of this case were reported previously (1).

\section{c) Failure to take mefloquine chemoprophylaxis correctly \\ Case 3}

A 24 years old Sapper erroneously took mefloquine $250 \mathrm{mg}$ daily for 3 days instead of weekly before deployment on exercise to Kenya. His medication container had been unlabelled. He developed anxiety, confusion, loss of concentration, memory impairment, depressed mood, lack of energy and restless legs (akathesia). Sleep was unaffected. No perceptual disturbance, panic, phobia or obsessiveness could be elicited. Appetite and body weight were maintained. A rash was noted on his upper arms. His symptoms persisted for two months but then began to improve over the following month.

\section{Case 4}

A 38 years old civilian journalist erroneously took mefloquine $250 \mathrm{mg}$ daily as a consequence of an incorrect prescription which was dispensed without question. After 5 days, he then experienced insomnia but continued to take daily mefloquine for 3 further days despite feeling unwell with loss of balance, anxiety and confusion. He then sought medical advice and stopped taking mefloquine and was assessed in a hospital accident and emergency department. A full physical examination, oximetry, blood glucose by rapid stick analysis and electrocardiogram were normal. Additional symptoms remembered 7 months later were headache, nausea, anorexia, fatigue, ? paraesthesia and abdominal discomfort.

Operation PALLISER resulted in over 1003 cases of malaria. One reason for this was that $\stackrel{\circ}{ }$ antimalarial chemotherapy was not started in $\bigcirc$ some cases by the time of deplaning in Senegal before transfer to Freetown, Sierra Leone (Lt Col DJ Vassallo - personal $\underset{\vec{\rho}}{\vec{\rho}}$ communication).

\section{d) Failure of mefloquine chemoprophylaxis}

Case 5

The age of this Private is not recorded nor are details of his antimalarial chemo- $\overrightarrow{0}$ prophylaxis. He would have been advised to $\overrightarrow{\vec{H}}$ take mefloquine $250 \mathrm{mg}$ weekly but $\stackrel{\omega}{\mathscr{\omega}}$ compliance cannot be assured. He deployed $\underset{\mathrm{\sigma}}{\overrightarrow{\mathrm{F}}}$ to Kenya on 13 February 1998. On 23 March 1998, he was admitted to hospital in ? Nairobi with an 11-day history of cough, t fever, wheezing, headache and vomiting. $\dot{\omega}$ Treatment for asthma had been given by a $\dot{c}$ regimental medical officer without relieving $ᄋ$ his symptoms. On admission, a blood film $\underset{ }{3}$ was examined for malarial parasites and $\mathrm{O}$ Plasmodium falciparum identified. ? Parasitaemia was in excess of $2 \% . \mathrm{He} \underset{\mathbb{D}}{\circ}$ received treatment with artemether $160 \mathrm{mg} N$ intramuscularly immediately and then $80 \mathrm{mg}$. intramuscularly daily for a further four days with mefloquine $500 \mathrm{mg}$ orally twice on the third day only. Asthma was treated with nebulised salbutamol and dexamethasone. $\mathrm{He}$ was discharged from hospital on 27 March 1998 taking Ventide (beclomethasone $\overrightarrow{\vec{P}}$ $50 \mathrm{mg}$ with salbutamol $100 \mu \mathrm{g}$ per metered dose) Inhaler 2 puffs thrice daily.

\section{Case 6}

The age of this Private is not recorded. He deployed to Kenya on 13 February 1998. On 19 March 1998, he was admitted with a 24 hour history of headache, neck pain, fever $\stackrel{\mathbb{J}}{F}$ and chills. He was taking mefloquine $250 \mathrm{mg}$ weekly as antimalarial chemoprophylaxis but had missed one dose about 5 days before becoming ill. Although initially negative, blood films prepared following a spike of 9 fever the day after admission showed $\frac{D}{0}$ trophozoites of Plasmodium falciparum. He was treated with artemether $160 \mathrm{mg}$ 。 intramuscularly immediately and then $80 \mathrm{mg}$ N intramuscularly daily for a further four days $\underset{\mathrm{C}}{\mathrm{W}}$ with doxycycline $100 \mathrm{mg}$ daily and Surbex-T (vitamins B and C) one daily orally for one $Q$ week. He was discharged on 27 March 1998 after two consecutive blood films showed no malarial parasites.

\section{Case 7}

This 27 year old Royal Marines Major commenced mefloquine $250 \mathrm{mg}$ weekly as antimalarial chemoprophylaxis on 12 March $\frac{8}{0}$ 1999 before deploying to Sierra Leone on 26 March 1999. On 27 March 1999, he became 을 unwell in Togo and on 30 March 1999, a 
diagnosis of falciparum malaria was made and treatment with quinine 1 gram intravenously daily for an uncertain number of days was commenced. At the beginning of May 1999, his case was reviewed locally and blood was tested by the ParaSight- $\mathrm{F}^{\mathrm{TM}}$ test for the presence of antibodies to the histidine-rich protein of Plasmodium falciparum. This was positive confirming his previous exposure. Thick and thin blood films showed no malarial parasites. Nevertheless, he was advised by a local physician to take quinine $500 \mathrm{mg}$ thrice daily for 5 days and then to continue with mefloquine chemoprophylaxis.

e) Restriction of aircrew to chloroquine and proguanil chemoprophylaxis

Case 8

This 30 years old Captain helicopter pilot Army Air Corps commenced antimalarial chemoprophylaxis with chloroquine $300 \mathrm{mg}$ weekly and proguanil $200 \mathrm{mg}$ daily on 30 January 1998. He deployed to Kenya on 13 February. Initially, he was based at an altitude of about $2200 \mathrm{~m}$ where there were

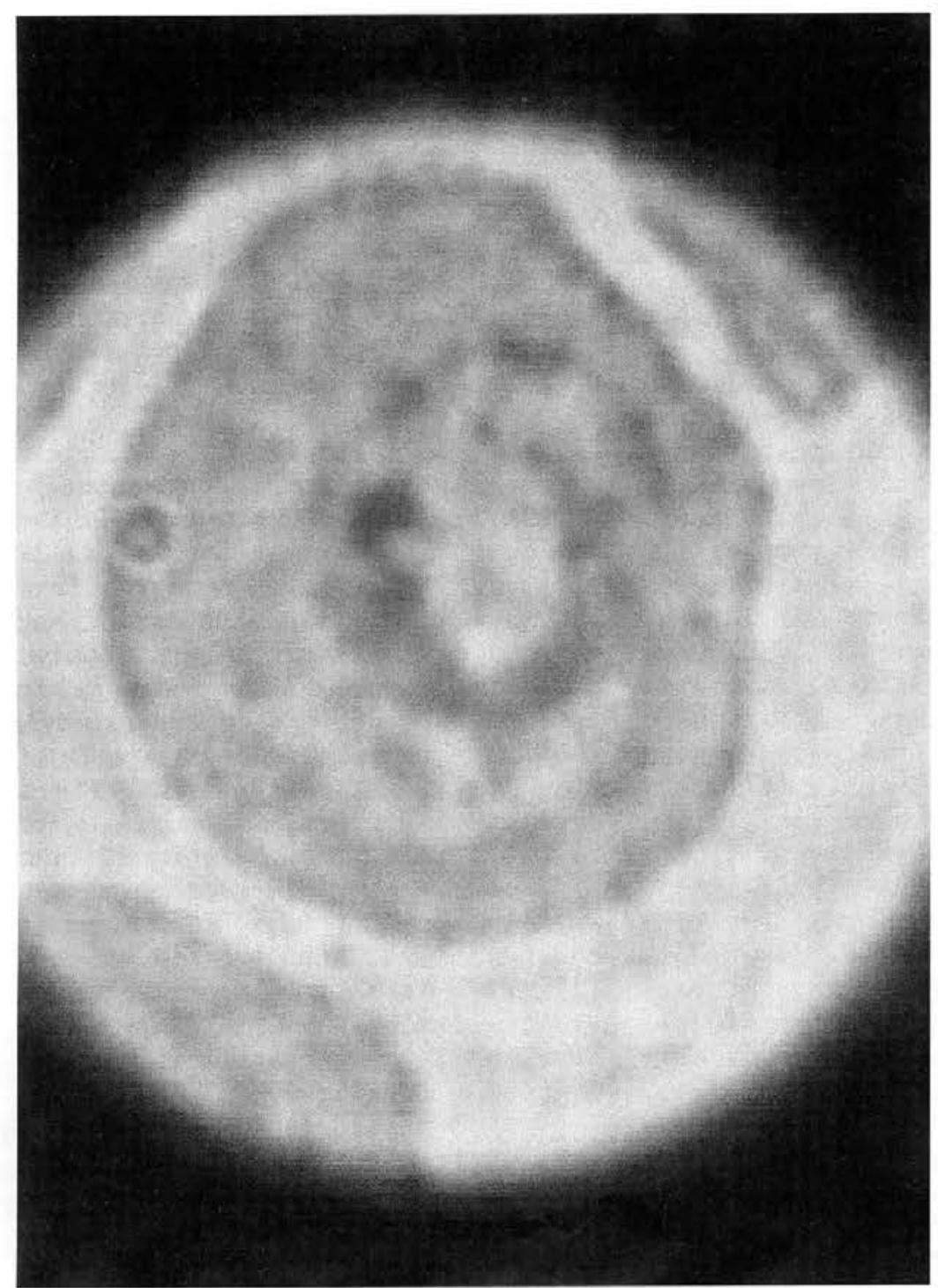

Fig 2. A digital photograph of a Plasmodium vivax schizont taken with less than optimal equipment and transmitted as an attached file by e-mail in the early days of development of telemedicine for British military medical operations. few mosquitoes but then moved about or $\stackrel{c}{6}$ month later to a base at a lower altitude of $1000 \mathrm{~m}$ where mosquitoes were numerou. He developed sudden onset of fever, chills and rigors and was evacuated to Nairobi. blood film was examined on $20 \mathrm{March}$ ard Plasmodium falciparum trophozoit identified. The level of parasitaemia was $0.5 \%$. $\mathrm{He}$ received treatment wi artemether $160 \mathrm{mg}$ intramusculardy immediately and then $80 \mathrm{mg}$ intramuscular需 daily for a further four days with mefloquirf $500 \mathrm{mg}$ orally twice on the third day on Two blood films were examined subseque tht to initial treatment and were negative. was discharged on $24 \mathrm{March}$ and continued antimalarial chemoprophylaxis wigh chloroquine and proguanil. He returned to UK about 2 April and finally stopp chemoprophylaxis on 30 April 1998. He hạs since remained well.

Operation PALLISER, a non-combatag civilian evacuation operation from Freetow Sierra Leone was commenced on $7 \mathrm{M}$ औy 2000. Within 6 weeks, 10 of 30 Chinoos helicopter aircrew whose antimalarid chemoprophylaxis was confined chloroquine $300 \mathrm{mg}$ weekly and proguares $200 \mathrm{mg}$ daily had contracted falciparu感 malaria (Lt Col DJ Vassallo - persone communication).

\section{f) Failure to diagnose malaria}

Case 9

A 26 years old L/Cpl RAMC was admittक्ष्त with fever ( $T=39.0$ Deg C) in Kosovo 늘 September 1999. He had served in Belize 1997 and had taken chemoprophylaxis for malaria (chloroquine $300 \mathrm{mg}$ weekly wiक़्र proguanil $200 \mathrm{mg}$ daily) as prescribed. He gave a history of four subsequent febri episodes which occurred at approximately monthly intervals. He had been admitted civilian hospitals on two occasions for the problem in the UK but no diagnosis hag been made. The febrile attacks we associated with rigors on occasions ard settled spontaneously. The first field of the first blood film examined contained 의 Plasmodium vivax schizont (Figure 2). He received 7 days of treatment with or quinine followed by primaquine $15 \mathrm{mg}$ daif for 14 days and made a good recovery.

g) Failure of malaria to respond to treatme with quinine

Case 10

An 18 years old civilian female with a negis father was admitted to a military hospit in UK with fever and impairment of consciousness and her blood film showed th presence of trophozoites of Plasmodiu falciparum. She had been admitted orte month earlier with falciparum malaria having returned from Equatorial Guinea an received treatment with quinine for 7 da followed by a single 3-tablet dose of Fansidär 
(sulphadoxine $500 \mathrm{mg}$ with pyrimethamine $25 \mathrm{mg}$ ) whereafter parasites had disappeared from the peripheral blood. Quinine resistance was assumed and treatment was given with artemether $160 \mathrm{mg}$ intramuscularly immediately and then $80 \mathrm{mg}$ intramuscularly daily for a further four days. There was a good clinical recovery over the next 24 hours and parasites disappeared from the peripheral blood. She remained well thereafter.

\section{Discussion}

Failure to take any chemoprophylaxis

No formal study has been undertaken to determine the reasons that combatant personnel fail to take antimalarial chemoprophylaxis. Nevertheless, there is an impression that some at least have an arrogant attitude to military medical advice, preferring to adopt their own counsel or to accept the advice of television journalists such as Ms Ann Robinson, the presenter of the BBC television programme Watchdog, where anecdotal evidence of adverse effects of mefloquine was presented in preference to rigorous medical studies (2). The solution to this problem will be to study attitudes rigorously and to formulate an appropriate plan of remedial education. This should include reference to data which suggest that the fall in cases of malaria imported into Britain by travellers to Kenya after 1993 was due to increasing use of mefloquine chemoprophylaxis (3).

\section{Side effects of antimalarial chemoprophylaxis}

The case (Case 2) presented here was reported previously (1). In this report, it was established that the frequency of a severe psychiatric reaction in soldiers was similar to that published previously. It needs to be emphasised that all drugs have their side effects and those used for prophylaxis against malaria are no exception. However, no cases of death arising from side effects of antimalarial chemoprophylaxis have been reported whereas deaths from malaria occur in the unprotected. Previous reports of uncontrolled observational studies which had many potential sources of bias $(4,5,6)$ have suggested that when taken prophylactically in sub-Saharan Africa, mefloquine $250 \mathrm{mg}$ weekly will prevent significantly more cases of falciparum malaria than other prophylactic regimens with a lower incidence of side effects. A prospective randomised double-'blind' trial of mefloquine $250 \mathrm{mg}$ weekly and chloroquine $300 \mathrm{mg}$ weekly with proguanil $200 \mathrm{mg}$ daily in British male soldiers who were not aviators failed to demonstrate any statistically significant difference in the incidence of side effects (7). The latter paper should be consulted for a full discussion of the adverse events associated with various antimalarial drugs. In relation to side effects, females seem to be more at risk of adverse effects of mefloquine than males and this may explain why military studies fail to demonstrate an increased frequency. Schlagenhauf et al. (8) assessed the frequency of adverse events with some impact on activity from mefloquine $250 \mathrm{mg}$ weekly after 1 or 2 doses. Of 394 evaluated volunteers, 44 $(11.2 \%)$ had one or more adverse events with females being approximately twice as likely to report problems as males. A retrospective assessment of adverse events occurring in 1214 adults advised to take mefloquine chemoprophylaxis and 1181 advised to take chloroquine-proguanil was undertaken. The number of recipients who experienced disabling (defined as preventing the traveller undertaking the activity for which the journey was made) side effects was $9(0.7 \%)$ in the mefloquine group and 1 $(0.09 \%)$ in the chloroquine-proguanil group. This difference was significant $(p=0.02)$. However, 7 of the mefloquine group were female (9).

Failure to take mefloquine chemoprophylaxis correctly

In the two cases presented, mefloquine $250 \mathrm{mg}$ was taken daily rather than weekly owing to the lack of (Case 3) or incorrect (Case 4) medical instructions. The possibility of employing an increased frequency of mefloquine administration to achieve protective blood levels quickly has been examined by giving $250 \mathrm{mg}$ daily for 3 days. A study (10) in trainee civil airline pilots showed that 1 ( $4 \%$ ) of 23 subjects developed dizziness, diarrhoea and influenza-like symptoms and withdrew from further study so that no cross-over placebo phase was conducted. There was a statistically significant increase in prevalence of neuropsychiatric symptoms ( $38 \%$ affected), inco-ordination $(8.9 \%$ affected) and depression ( $17.8 \%$ affected) in 46 US Marines given mefloquine $250 \mathrm{mg}$ daily for 3 days when compared with 156 controls who received a placebo tablet daily for the first 2 days after the first mefloquine tablet (11). The risk of adverse effects was doubled when this rapid induction regimen was attempted although none of these fit marines was militarily disabled. There is, therefore, good evidence that taking prophylactic mefloquine daily will result in an increased prevalence of symptoms and should be avoided whenever possible. Nevertheless, this 3-day induction regimen will achieve protective mefloquine levels (11) which have been found to be $>500 \mathrm{ng} / \mathrm{ml}(4,12)$.

\section{Failure of mefloquine chemoprophylaxis}

No form of antimalarial chemoprophylaxis is guaranteed to provide complete protection against malaria. Assessment of success or failure of preventive measures depends primarily on the history of compliance 
provided by the patient and this is only occasionally assessed objectively by measurement of blood drug levels. Hence, it is always difficult to be certain whether a case of breakthrough malaria is due to failure of chemoprophylaxis or failure of compliance. Certainly soldiers may not be fully compliant with mefloquine chemoprophylaxis. It was found that compliance was not complete in at least $12.8 \%$ at 2 weeks and this rose to at least $31 \%$ at 8 weeks (7). Nevertheless, failure of mefloquine chemoprophylaxis has been documented in Africa since 1990 (13) and on the borders of Thailand with Myanmar (formerly Burma) and Cambodia since $1991(14,15,16)$. Malaria arising during mefloquine chemoprophylaxis is more likely to be a drug failure given the long half-life of 18 days (10). This may be associated with a delay in clinical manifestation of malaria (17). The cases presented (Cases 5-7) show a range of certainty concerning compliance with the latter two cases being most likely to be a failure of the drug to provide adequate protection. A delay of 5 days in taking mefloquine (Case 6) should still result in a protective (>500ng/ml) level (4). Apart from chloroquine $300 \mathrm{mg}$ weekly and proguanil $200 \mathrm{mg}$ daily which, given the frequency of malaria in aviators provided with this, is clearly inadequate in Sierra Leone, doxycycline $100 \mathrm{mg}$ daily is the only alternative licensed (although not for this indication) drug and even this has some side effects (See below). This and others (eg Savarine [chloroquine $200 \mathrm{mg}$ with proguanil $100 \mathrm{mg}$ ] and Malarone [atovaquone $250 \mathrm{mg}$ with proguanil $100 \mathrm{mg}$ ]) may be licensed eventually.

Restriction of aircrew to chloroquine and proguanil chemoprophylaxis

Assuming the prevalence of malaria in military aviators operating in sub-Saharan Africa is confirmed on formal assessment, the current situation where a relatively ineffective form of chemoprophylaxis is employed is not acceptable. Quite apart from the adverse effect on military airpower, it is unethical to expose personnel to an increased risk of a potentially life-threatening disease. There is little data to support the view that aviators should not receive mefloquine. Of 354 evaluated volunteer travellers, 31 (7.9\%) had neuropsychiatric symptoms with some impact on activity which included sleep disturbance and decreased concentration after 1 or 2 doses of mefloquine $250 \mathrm{mg}$ weekly. When compared with matched controls who had also received mefloquine but experienced no adverse reaction, no significant difference in psychomotor performance, a computer-based test including assessment of hand-eye coordination, could be demonstrated. There was no change in psychomotor performance in those who did have symptoms after 1-2 doses of mefloquine when reassessed $3 \geq$ months later after their last dose of mefloquine. Hence, although mefloquine $\bar{z}$ may cause neuropsychiatric symptoms this $\frac{\mathbb{Q}}{2}$ does not appear to affect psychomotor $?$ performance (8). It was not possible to demonstrate any changes in the flight?

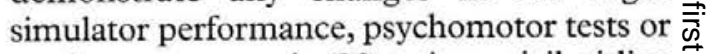
tendency to sway in 22 trainee civil airline pilots after a 3-week period of mefloquine 흠 and 4-6 months later in a double-blind $\frac{\bar{\sigma}}{\bar{\rho}}$ placebo cross-over study despite the fact that $\stackrel{\mathbb{Q}}{\complement}$ $3(13 \%)$ experienced sleep-related symptoms \% with mefloquine. However, one subject $\overrightarrow{0}$ experienced dizziness, diarrhoea and flu-like $\overrightarrow{\overrightarrow{.}}$ symptoms during the initial 3-day rapid $\vec{\omega}$ induction phase of daily dosing with mefloquine and had no performance studies.

As a group, potential aviators are assessed carefully. Any suggestion of psychiatric $\vec{t}$ morbidity, psychological unsuitability or epilepsy prevents flying and, hence, they should have a reduced risk, if anything, of ${ }_{0}^{\mathrm{O}}$ side effects from mefloquine. If concerns do still exist about use of mefloquine in aviators, $\vec{O}$ one well conducted study suggested that doxycycline $100 \mathrm{mg}$ daily may offer similar protection to mefloquine $250 \mathrm{mg}$ weekly (9). Doxycycline does cause dizziness. One study 8 showed this to be $5 \%$ (cf. mefloquine $7 \%$, 19) and another, $19 \%$ (cf. mefloquine $11 \%$, 20) of subjects.

\section{Failure to diagnose malaria}

Few excuses are acceptable for failure to diagnose malaria although laboratory윽 confirmation can be difficult on occasions. Fever in a patient with an appropriate travel: history, whether or not any precautions were taken should be sufficient for this diagnosis to be considered seriously and a trial of treatment given. Absence of evidence of an $\frac{\bar{\sigma}}{2}$ alternative diagnosis and a history of $\frac{\mathscr{Q}}{\bar{F}}$ recurrent fever as in the case presented (Case 9) are additional helpful features compatible 3 . with this diagnosis. On review of cases of malaria seen at Coppett's Wood Hospital (21), $96 \%$ had fever but only $8 \%$ had any응 short term periodicity (so-called 'tertian' or $>$ 'quartan' fever), so absence of this feature is no bar to this diagnosis. At present, the only $N^{N}$ commercially available immunological tests $N$ for the presence of antibody to PlasmodiumN్ are confined to falciparum (ParaSight- $\mathrm{F}^{\mathrm{TM}} \mathrm{\sigma}$ and ICT Malaria P.f ${ }^{\mathrm{rM}}$ card test). Similar tests for other species should become available soon. The limitation is that the tests? provide evidence of previous infection and $\bar{T}$ do not prove whether it is current or not. $\frac{O}{\mathbb{D}}$

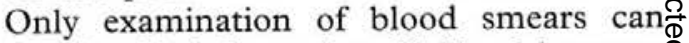
provide this information. Civilian laboratory technicians are likely to have less experience of malarial parasites than their militaryo counterparts. Capillary blood is more likely to yield trophozoites which, in any case, are far less numerous in Plasmodium ovale and 
malariae infections. Any or all of these factors could have contributed to the failure to diagnose this case, which, nevertheless, was diagnosed under the more basic conditions of a military field hospital suggesting that experience may have been the crucial element in establishing the diagnosis.

\section{Failure of malaria to respond to treatment with quinine}

The case (Case 10) presented here is an example of R1 resistance - the weakest level - where parasitized red cells disappear from the peripheral blood (below the so-called patency level) only to return after a week or more. The patient received the standard quinine dosage of $20 \mathrm{mg} / \mathrm{kg}$ body weight intravenously over 4 hours with $10 \mathrm{mg} / \mathrm{kg}$ body weight over 4 hours every 8 hours. After 48 hours, the route of administration was changed from intravenous to oral. It is disconcerting that Case 10 failed treatment with quinine. It is possible that primary cure might have been achieved by adding a tetracycline (eg oxytetracycline $250 \mathrm{mg}$ every 6 hours). Had that not been successful then treatment with an artemisinin derivative would be appropriate as was used successfully here. Alternatively, Malarone (atovaquone $250 \mathrm{mg}$ with proguanil $100 \mathrm{mg}$ ) 4 tablets daily for 3 days is a convenient oral treatment of proven efficacy (22) may also have achieved a cure. Returning to prophylaxis, a single tablet of Malarone daily may well provide good protection against falciparum malaria, although this is not adequately assessed yet, with a superior side effect profile (23).

\section{Conclusion}

All the problems identified are worthy of further study to define their magnitude. The remedies that follow are interim suggestions. Compliance with antimalarial chemoprophylaxis must be improved by a process of education. There are no data to indicate that weekly mefloquine should not be employed in sub-Saharan Africa in fit male military personnel, including aircrew, even when preceded by a rapid induction of three daily doses. An alternative is daily doxycycline. Despite reported symptoms, there is no evidence that these drugs impair military performance. Diagnostic rapid immunological tests for falciparum malaria are helpful and should be in widespread use. Vigilance should be maintained for quinine resistant malaria. Malarone is appropriate in these circumstances when the patient can take oral medication. Otherwise, artemether can be given by intramuscular injection.

\section{References}

1. Croft AMJ, World MJ, "Neuropsychiatric reactions with mefloquine chemoprophylaxis", Lancet 1996; 346: 326

2. Clift S, Grabowski P. "Malaria prophylaxis and the media", Lancet, 1996; 348: 344

3. Behrens RH, Bradley DJ, Snow RW, Marsh K. "Impact of UK malaria prophylaxis policy on imported malaria", Lancet, 1996; 348: 344-345

4. Lobel HO, Bernard KW, Williams SL, Hightower AW, Patchen LC, Campbell CC. "Effectiveness and tolerance of long-term malaria prophylaxis with mefloquine", भAMA 1991; 265: 361-364

5. Lobel HO, Miani $M$, Eng T, Bernard KW, Hightower AW, Cambell CC. "Long-term malaria prophylaxis with weekly mefloquine", Lancet 1993; 341: 848-851

6. Steffen R, Fuchs E, Schildknecht J, Naef U, Funk $\mathrm{M}$, Schlagenhauf $\mathrm{P}$ et al. "Mefloquine compared with other malaria chemoprophylactic regimens in tourists visiting East Africa", Lancet 1993; 341: 1299-1303

7. Croft AMJ, Clayton TC, World MJ. "Side effects of mefloquine prophylaxis for malaria: an independen randomised trial", Trans R Soc Trop Med Hyg 1997; 91: 199-203

8. Schlagenhauf $\mathrm{P}$, Steffen R, Lobel H, Johnson R, Letz R, Tschopp A et al. "Mefloquine tolerability during chemoprophylaxis: focus on adverse event assessments, stereochemistry and compliance", Trop Med Int Health 1996; 1: 485-494

9. Barrett PJ, Emmins PD, Clarke PD, Bradley DJ. "Comparison of adverse events associated with use of mefloquine and combination of chloroquine and proguanil as antimalarial prophylaxis: postal and telephone survey of travellers", Brit Med f 1996; 313: $525-528$

10. Schlagenhauf P, Lobel H, Steffen R, Johnson R, Popp K, Tschopp A et al. "Tolerance of mefloquine by Swissair trainee pilots", Am $\mathrm{f}$ Trop Med Hyg 1997; 56: 235-240

11. Boudreau E, Schuster B, Sanchez J, Novakowski W, Johnson R, Redmond D et al. "Tolerability of prophylactic Lariam ${ }^{\mathbb{R}}$ regimens" Trop Med Parasitol 1993; 44: 257-265

12. Slutsker L, Khoromana CO, Payne D “Mefloquine therapy for Plasmodium falciparum malaria in children under 5 years of age in Malawi: in vivo/in vitro efficacy and correlation with parasitological outcome", Bull World Health Organ 1990; 68: 53-59

13. Ringwald P, Bartczak S, Le Bras J, Bricaire F, Matheron S, Bauchet $\mathrm{J}$, et al. "Failure of antimalarial prophylaxis with mefloquine in Africa" Trans $R$ Soc Trop Med Hyg 1990; 84: 348-349

14. Hopperus Buma AP, van Thiel PP, Lobel HO, Ohrt C, van Ameijden EJ, Veltink RL et al. " Long-term malaria chemoprophylaxis with mefloquine in Dutch marines in Cambodia", f Infect Dis 1996; 173: 1506-1509

15. Fontanet AL, Johnston BD, Walker AM, Bergqvist $Y$, Hellgren U, Rooney W "Falciparum malaria in eastern Thailand: a randomised trial of the efficacy of a single dose of mefloquine", Bull World Health Organ 1994; 72: 73-81

16. Nosten F, ter Kuile F, Chongsuphajaisiddhi T, Luxemburger C, Webster HK, Edstein $M$ et al. "Mefloquine-resistant falciparum malaria on the Thai-Burmese border", Lancet 1991; 337: 11401143

17. Reyburn H, Behrens RH, Warhurst D, Bradley DJ. "The effect of chemoprophylaxis on the timing of onset of falciparum malaria", Trop Med Int Health 1998; 3: 281-285

18. Ohrt C, Richie TL, Widjaja H, Shanks GD, Fitriadi J, Fryauff DJ et al. "Mefloquine compared with doxycycline for the prophylaxis of malaria in Indonesian soldiers", Ann Int Med 1997; 126: 963972

19. Arthur JD, Shanks GD, Echeverria P. "Mefloquine prophylaxis". Lancet 1990; 340: 672 
20. Sanchez JL, De Fraties RF, Sharp TW, Hanson RK "Mefloquine or doxycycline prophylaxis in US troops in Somalia", Lancet 1993; 343: 1021

21. Brook MG, Bannister BA. "The clinical features of malaria" Communicable Disease Review 1993; 3: 2831
22. Radloff PD, Philipps J, Nyeki M, Hutchinson D, D Kremsaw PG. "Atovaquone and proguanil for $D$ Plasmodium falciparum malaria" Lancet 1996; 347: 1511-1514

23. Høghe B, Clarke PD, Camus D, Nothduift $H D, 3$ Overbosch D, Günther $M$ et al. "Atovaquone-尺 proguanil versus chloroquine-proguanil for malaria prophylaxis in non-immune travellers: a randomised음 double-blind study" Lancet 2000; 356: 1888-1894 क्? 